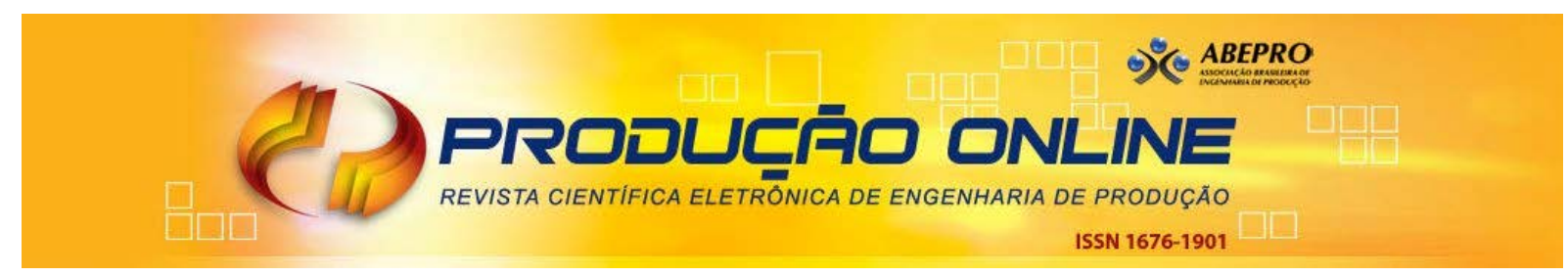

\title{
REVISÃO DE FERRAMENTAS PARA AVALIAÇÃO ERGONÔMICA
}

\section{REVIEW OF ERGONOMIC ASSESSMENT TOOLS}

\author{
Dalila Giovana Pagnoncelli Laperuta* E-mail: dalila@utfpr.edu.br \\ Gilson Adamczuk Oliveira* Ea-mail? gilson@utfpr.edu.br \\ Sergio Luiz Ribas Pessa* E-mail: slpessa@utfpr.edu.br \\ Roger Poglia da Luz* E-mail: roger@utfpr.edu.br \\ *Universidade Tecnológica Federal do Paraná (UTFPR), Pato Branco, PR
}

\begin{abstract}
Resumo: O propósito deste artigo é analisar os métodos/ferramentas de avaliação ergonômica por meio da identificação e definição dos métodos, incidência de publicações e análise de especialistas. Utilizando ajuste das séries históricas por ajuste de séries temporais, obteve-se uma tendência linear ascendente em publicações para 23 dos 24 métodos identificados neste estudo, sendo os mais frequentes: NIOSH, fanger, NASA-TLX, OWAS, REBA e RULA. O método NIOSH, o mais incidente em publicações, foi muito bem avaliado pelo grupo, tendo sido utilizado por todos os especialistas consultados. Os métodos NASA-TLX $\left(3^{\circ}\right)$ e REBA $\left(5^{\circ}\right)$ também foram bem avaliados e utilizados pelos ergonomistas, ficando acima da média de avaliação e uso. Embora a consulta aos especialistas gere resultados semelhantes à investigação quantitativa, sua maior contribuição é de caráter qualitativo, cujas percepções fundamentam a análise crítica dos métodos de avaliação ergonômica sob a luz da literatura. Concluiu-se que, em complemento a essas informações, é preciso considerar a particularidade da tarefa e a experiência do profissional de ergonomia no processo de escolha do método de avaliação ergonômica. Por fim, identificou-se muitos métodos semelhantes, derivados ou associados entre si, sendo necessário estudar o processo de análise e avaliação ergonômica em busca de perspectivas para uma abordagem de avaliação ergonômica unificada (estudos futuros).
\end{abstract}

Palavras-chave: Avaliação ergonômica. Ferramentas ergonômicas. Ergonomia

Abstract: This paper analyzes the methods of ergonomic evaluation by identifying and defining the methods, frequency of publications and expert analysis. Using adjustment of historical series by adjustment of time series, we obtained an upward linear trend in publications for 23 of the 24 methods identified in this study, the most common being: niosh, fanger, nasa-tlx, OWAS, reba and rula. The niosh method, the most frequent in publications, was very well evaluated by the group, having been used by all the experts consulted. Methods nasa-tlx (3rd) and reba (5) were also well evaluated and used by ergonomists, being above average in evaluation and use. Although the consultation of experts generates results similar to quantitative research, the experts' greatest contribution is qualitative, as their perceptions are based on the critical analysis of ergonomic assessment methods in the light of the literature. It was concluded that, in addition to this information, it is necessary to consider the particularity of the task and the experience of the ergonomics professional in the process of choosing the ergonomic assessment method. Finally, we identified many similar methods, derived from or associated with each other, and found it necessary to study the process of analysis and ergonomic evaluation in search of prospects for a unified ergonomic assessment approach (future studies).

Keywords: Ergonomic assessment. Ergonomic Assessment tools, Ergonomics. 


\section{INTRODUÇÃO}

A ergonomia é a área da engenharia que se concentra em estudar as relações entre o homem e o trabalho, no intuito de torná-las benéficas: condições de trabalho que garantam a saúde física e mental do trabalhador sem prejuízo da produtividade. Após os avanços ergonômicos em postos de precisão, ação contínua e atenção, motivados pela II Guerra Mundial, surgiu então a ergonomia, uma área interdisciplinar que contribui para melhorar a eficiência, a confiabilidade e a qualidade das operações. A fim de avaliar essa adequação, considera as posturas e os movimentos corporais (bases biomecânicas, fisiológicas e antropométricas), os fatores ambientais (ruído, vibrações, iluminação, clima, substâncias químicas), informação e operação (o usuário, as informações, características, percepções, sentidos, controles, compatibilidade entre informação e operação, expectativa do usuário, usabilidade e diálogos), e as relações entre cargos e tarefas (organização do trabalho). Guérin et al. (2006) definem, como categorias observáveis da ergonomia na organização os deslocamentos, a direção do olhar, as comunicações, as posturas, as observações em termo de ações ou tomadas de informação, os observáveis relativos ao sistema técnico e ao contexto e a dimensão coletiva nos registros de observação. Segundo Másculo e Vidal (2011), a Ergonomia na empresa resulta de uma atuação planejada, mesmo que intuitiva, ou seja, é preciso pensar nas ações imediatas e futuras.

Os ergonomistas são profissionais que adquirem conhecimentos na área ao longo dos anos, seja por graduação, treinamentos, especializações ou certificações. Eles atuam no ensino, instituições de pesquisa, órgãos normativos, prestação de serviços e no setor produtivo (DUL; WEERDMEESTER, 2004). Podem ser exemplos de ergonomistas: engenheiro de segurança do trabalho, fisioterapeuta, médico do trabalho, pesquisador, fisiologista e técnico em segurança do trabalho. Esses profissionais atuam em domínios especializados, dentro das três áreas da ergonomia. São elas a ergonomia física (anatomia, antropometria, fisiologia e biomecânica), ergonomia cognitiva (processos mentais percepção, memória, raciocínio e resposta motora) e organizacional (otimização de sistemas sociotécnicos, estruturas organizacionais, políticas e processos). Dessas áreas derivam as modalidades de intervenção ergonômica (WISNER, 1987), que atuam na 
correção (problemas na segurança e conforto dos trabalhadores ou na insuficiência da produção), concepção (especificação de produtos), e mudança (acompanhamento e avaliação do processo por meio de programa permanente. $\mathrm{Na}$ prática, de acordo Laville (1977), a aplicação ergonômica acontece em três etapas. Na primeira, é feita a análise do quadro técnico, econômico, social e político, onde o empresário, seja por cumprimento das normativas de regulação das condições ergonômicas laborativas, por demanda interna (grupos, comitês, comissões, departamentos) ou auditorias, solicita uma análise ergonômica na empresa. $\mathrm{Na}$ segunda etapa, ocorre a análise da demanda, momento em que o profissional de ergonomia realiza uma análise ergonômica do trabalho para identificar quais são as demandas ergonômicas que requerem atenção. Por fim, na terceira etapa ocorre a análise ergonômica do problema. Nesta etapa, estabelece-se um diagnóstico especializado para cada demanda por meio de métodos de estudos sistemáticos, medir a necessidade de intervenção ergonômica.

Este artigo tem seu foco na terceira etapa, fase em que o especialista seleciona os métodos/ferramentas e normas que vão instrumentar a avaliação ergonômica. Existe um grande número de métodos, cujas revisões bibliográficas dificilmente os reúnem em quantidade. Também é possível notar um grupo de métodos semelhantes entre si, ou métodos diferentes cujas avaliações parcialmente se sobrepõem. Portanto, não havendo revisões abrangentes desses métodos, não é possível compará-los ou condensá-los. Também há uma indefinição em relação à nomenclatura: são chamados de ferramentas, métodos, instrumentos, técnicas, dificultando sua organização e classificação. Essas foram as motivações para o desenvolvimento desse estudo. A seção 1.1 esclarece a definição de método considerada nesta pesquisa, define os métodos encontrados e os classifica. Em Materiais e Métodos, todos os critérios e passos realizados na condução desta pesquisa são detalhados, e os dados coletados são tratados a procura de respostas: Quais os métodos mais utilizados? Para que são usados? Qual o comportamento das publicações sobre métodos de avaliação ergonômica ao longo dos anos? Qual a opinião dos especialistas? Acredita-se que essas respostas contribuirão para a análise crítica dos métodos ergonômicos em busca de novas abordagens. 


\subsection{Métodos/Ferramentas de Avaliação Ergonômica}

Desde a década de 70 vêm sendo desenvolvidos roteiros para execução de uma análise ergonômica, alguns dos quais se converteram em modelos e serviram de base para outras propostas metodológicas (LIMA, 2004). Wisner (1987) fez referência aos métodos como protocolos de avaliação das condições de trabalho. Para lida (2005), o método é um procedimento para estabelecer a relação entre causa e efeito, sendo composto pelas etapas que vão da hipótese ao resultado. $\mathrm{Na}$ prática, a avaliação ergonômica do trabalho é realizada através de métodos/ferramentas e normas, que consideram um grupo de condições de trabalho e um foco específico, melhor definida por Másculo e Vidal (2011): "O método ergonômico consiste no uso de recursos dos campos de conhecimento que possibilitem averiguar, levantar, analisar e sistematizar o trabalho e suas condições, através de instrumentos qualitativos e quantitativos". Essa definição é alinhada com o significado da palavra "método", definindo-o como o conjunto dos meios dispostos convenientemente para alcançar um fim e chegar a um conhecimento científico (MICHAELIS, 2009). Essa definição embasará a classificação dos métodos para o desenvolvimento deste artigo; entretanto, é válida para este estudo e não representa um novo conceito. No intuito de contribuir para a fluidez, e ainda, respeitar as diferentes nomenclaturas, o termo ferramenta será utilizado como sinônimo de método de avaliação ergonômica. Nos quadros de 1 a 5 são apresentados os 24 métodos/ferramentas de avaliação ergonômica revisados neste artigo, e suas características fundamentais, classificados como métodos com base nas definições adotadas e agrupados por tipo de avaliação. 
Quadro 1 - Métodos/ferramentas ergonômicas para avaliação de riscos posturais e posto de trabalho. Elaborado pelo autor a partir de múltiplas fontes

(Continua)

\begin{tabular}{|c|c|c|}
\hline \multicolumn{3}{|c|}{ FERRAMENTAS PARA AVALIAÇÃO DE RISCOS POSTURAIS E POSTO DE TRABALHO } \\
\hline Método & Definições & Procedimentos \\
\hline \multirow[t]{2}{*}{$\begin{array}{l}\text { Checklist de } \\
\text { Couto }\end{array}$} & $\begin{array}{l}\text { São utilizados para avaliação de riscos } \\
\text { para trabalhos manuais, DORT, } \\
\text { lombalgias, trabalhos informatizados, } \\
\text { condição ergonômica e condição } \\
\text { biomecânica. }\end{array}$ & $\begin{array}{l}\text { Em observação ao checklist, percebe-se que a } \\
\text { ferramenta permite uma avaliação simplificada do } \\
\text { fator biomecânico no risco para distúrbios } \\
\text { musculoesqueléticos de membros superiores } \\
\text { relacionados ao trabalho. Neste checklist, as } \\
\text { perguntas avaliam seis aspectos: sobrecarga } \\
\text { física, força com as mãos, postura no trabalho, } \\
\text { posto de trabalho e esforço estático, repetitividade } \\
\text { e organização do trabalho e ferramenta de } \\
\text { trabalho. }\end{array}$ \\
\hline & $\begin{array}{l}\text { Constitui-se de perguntas que são } \\
\text { avaliadas percentualmente em intervalos, } \\
\text { indicando resultados de péssimo - alto } \\
\text { risco (abaixo de 31\%) à excelente - } \\
\text { ausência de risco (próximo a 100\%) } \\
\text { (SOARES; SILVA, 2012) }\end{array}$ & $\begin{array}{l}\text { Avaliação das condições ergonômicas em postos } \\
\text { de trabalho e ambientes informatizados - Versão } \\
2013 \text {. Este checklist avalia os aspectos } \\
\text { relacionados à estação de trabalho, sistema de } \\
\text { trabalho e ambiente. }\end{array}$ \\
\hline $\begin{array}{l}\text { EWA, } \\
\text { também } \\
\text { chamado de } \\
\text { FIOH }\end{array}$ & 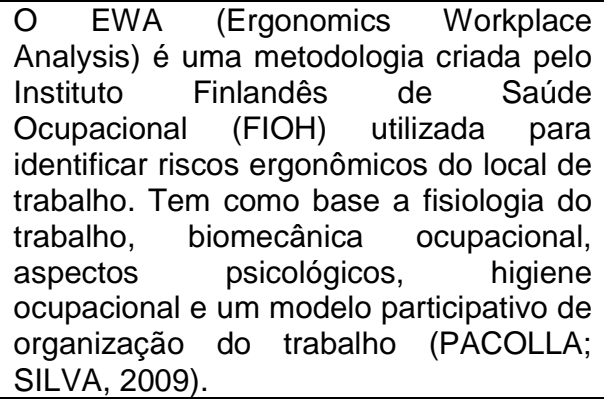 & $\begin{array}{l}\text { Avalia os seguintes aspectos: espaço de trabalho, } \\
\text { atividade física geral, levantamento de cargas, } \\
\text { posturas de trabalho e movimentos, risco de } \\
\text { acidente, satisfação com o trabalho, restrições, } \\
\text { comunicação entre trabalhadores, tomada de } \\
\text { decisão, repetitividade, atenção, iluminação, } \\
\text { temperatura ambiente e ruído. }\end{array}$ \\
\hline $\begin{array}{l}\text { LUBA - } \\
\text { Loading on } \\
\text { the Upper } \\
\text { Body } \\
\text { Assessment }\end{array}$ & $\begin{array}{l}\text { Avalia cargas relacionadas à postura da } \\
\text { parte superior do corpo (mão, braço, } \\
\text { pescoço e costas), sendo a postura de } \\
\text { uma parte do corpo classificada de } \\
\text { acordo com os ângulos das articulações } \\
\text { (ROMAN-LIU, 2014). }\end{array}$ & $\begin{array}{l}\text { Considera os índices de desconforto, expressos } \\
\text { através de pontuação numérica, e o número } \\
\text { máximo de movimentos em posturas estáticas, no } \\
\text { intuito de avaliar estresse postural e atuar na } \\
\text { prevenção de distúrbios osteomusculares (KEE; } \\
\text { KARWOWSKI, 2001). }\end{array}$ \\
\hline OCRA & $\begin{array}{l}\text { Método desenvolvido pela Dra. Daniela } \\
\text { Colombini e Dr. Enrico Occhipinti, na } \\
\text { Clínica de Lavoro de Milão em 2000, que } \\
\text { por meio de um checklist avalia e } \\
\text { recomenda ações para prevenção de } \\
\text { riscos decorrentes de esforços } \\
\text { repetitivos. Também considera fatores } \\
\text { mecânicos, ambientais e organizacionais } \\
\text { que forneçam evidências da relação de } \\
\text { causalidade com DORT (COLOMBINI; } \\
\text { OCCHIPINTI, 2006). }\end{array}$ & $\begin{array}{l}\text { Também chamado de índice OCRA, baseia-se na } \\
\text { relação entre Ações Reais Técnicas (ATA), } \\
\text { obtidos por meio da análise de tarefas e ações de } \\
\text { Referência Técnica (RTA). O valor RTA é obtido } \\
\text { levando-se em conta a frequência e repetitividade } \\
\text { de movimentos dos membros superiores, uso } \\
\text { excessivo da força, tipo de postura inadequada ou } \\
\text { falta de variação postural, períodos de } \\
\text { recuperação insuficientes e fatores adicionais, tais } \\
\text { como vibração e compressão do tecido localizado. } \\
\text { O método OCRA fornece dois índices separados } \\
\text { (ombro e cotovelo / pulso / mão) para cada um } \\
\text { dos lados direito e esquerdo do corpo } \\
\text { (CHIASSON, 2012). }\end{array}$ \\
\hline
\end{tabular}

Revista Produção Online. Florianópolis, SC, v. 18, n. 2, p. 665-690, 2018. 
Quadro 1 - Métodos/ferramentas ergonômicas para avaliação de riscos posturais e posto de trabalho

(Continuação)

\begin{tabular}{|c|c|c|}
\hline \multicolumn{3}{|c|}{ FERRAMENTAS DE AVALIAÇÃO PARA RISCOS POSTURAIS E POSTO DE TRABALHO } \\
\hline Método & Definições & Procedimentos \\
\hline OREGE & $\begin{array}{l}\text { Desenvolvido na França pelo INRS } \\
\text { (Instituto Nacional de Pesquisa de } \\
\text { Segurança), é um método de } \\
\text { identificação e avaliação cujo objetivo é } \\
\text { quantificar tensões biomecânicas } \\
\text { representadas por forças, posturas } \\
\text { constrangedoras e movimento repetitivo, } \\
\text { sendo baseado na observação do } \\
\text { operador, sua percepção das demandas } \\
\text { e indicações. É realizada a partir da } \\
\text { avaliação de força, vigor e repetitividade } \\
\text { (APTEL, 2008). }\end{array}$ & $\begin{array}{l}\text { Para cada ação considerada, à força atribui-se um } \\
\text { valor de } 0 \text { a } 10 \text { em uma ficha de avaliação, } \\
\text { preenchidas uma pelo pesquisador e outra pelo } \\
\text { operador, separadamente, sendo a avaliação } \\
\text { realizada com base nas duas fichas. Para cada } \\
\text { aspecto preocupante, o pesquisador observa os } \\
\text { movimentos dos membros superiores do operador } \\
\text { (pescoço, ombro, cotovelo e punhos), atribuindo } \\
\text { valores de } 1 \text { (aceitável), } 2 \text { (não recomendado) e } 3 \\
\text { (a evitar) para cada articulação, considerando a } \\
\text { lateralidade, impressas em figuras que } \\
\text { representam as pontuações e os respectivos } \\
\text { ângulos. Já os movimentos repetitivos dos } \\
\text { membros superiores são avaliados numa escala } \\
\text { de } 0 \text { a 10, num período de tempo, duplamente e } \\
\text { separadamente avaliados em fichas, cuja } \\
\text { pontuação também é representada por figuras. }\end{array}$ \\
\hline $\begin{array}{l}\text { OWAS - } \\
\text { Ovako } \\
\text { Working } \\
\text { Posture } \\
\text { Analysing } \\
\text { System }\end{array}$ & $\begin{array}{l}\text { Foi desenvolvido na Finlândia entre } 1974 \\
\text { e 1978, no intuito de analisar as posturas } \\
\text { corporais durante as atividades no } \\
\text { trabalho. Os dados para a aplicação } \\
\text { desse método podem ser coletados } \\
\text { através de observação direta (em } \\
\text { campo) ou indireta (por vídeo), e as } \\
\text { fases da atividade podem ser } \\
\text { categorizadas em um código de seis } \\
\text { dígitos. Após a categorização, o método } \\
\text { calcula e classifica a carga de trabalho } \\
\text { em quatro categorias, determinando } \\
\text { ainda as medidas a serem adotadas } \\
\text { (MÁSCULO; VIDAL, 2011). }\end{array}$ & $\begin{array}{l}\text { A partir de análises fotográficas, foram } \\
\text { colecionadas } 72 \text { posturas típicas (dorso, braços e } \\
\text { pernas e carga/força) que ocorrem em uma } \\
\text { indústria pesada, sendo codificadas de } 1 \text { a } 4 \text {, } \\
\text { onde } 1 \text { é não patológico e } 4 \text { indica que } \\
\text { providências imediatas devem ser tomadas. } \\
\text { Também se considera a frequência e o tempo } \\
\text { despendido em cada postura, a fim de avaliar o } \\
\text { efeito resultante sobre o sistema } \\
\text { musculoesquelético. }\end{array}$ \\
\hline $\begin{array}{l}\text { QEC - Quick } \\
\text { Exposure } \\
\text { Check }\end{array}$ & $\begin{array}{l}\text { Baseia-se na postura, onde a } \\
\text { combinação da avaliação do observador } \\
\text { com respostas do trabalhador para } \\
\text { questões fechadas, permite que os } \\
\text { fatores de risco MSD para as costas, } \\
\text { braços, pescoço e extremidades } \\
\text { superiores a uma estação de trabalho } \\
\text { sejam avaliados (CHIASSON, 2012). }\end{array}$ & $\begin{array}{l}\text { Avalia a postura, a força aplicada, a frequência, a } \\
\text { duração, os movimentos e os fatores psicológicos } \\
\text { relacionados à tarefa. É aplicado em duas etapas: } \\
\text { 1) avaliação das posturas por meio de checklist, } \\
\text { 2) questionário aplicado ao trabalhador. } \\
\text { Os níveis de exposição são obtidos através do } \\
\text { cruzamento das etapas. }\end{array}$ \\
\hline $\begin{array}{l}\text { Questio- } \\
\text { nário Bipolar }\end{array}$ & $\begin{array}{l}\text { O questionário bipolar de fadiga foi } \\
\text { elaborado pelo médico Hudson Couto em } \\
\text { 1995. Ele é composto por } 3 \\
\text { questionários/etapas, sendo o primeiro } \\
\text { aplicado no início da jornada, o segundo } \\
\text { na hora de saída para o almoço e o } \\
\text { terceiro no final da jornada (COSTA; } \\
\text { SOUZA, 2014). }\end{array}$ & $\begin{array}{l}\text { A pontuação varia de } 1 \text { a } 7 \text {, sendo } 1 \text { a esquerda e } \\
7 \text { à direita; quanto mais à direita, maior a fadiga. A } \\
\text { análise dos questionários é realizada de forma } \\
\text { qualitativa, observando: a fadiga acumulada ( } 4 \\
\text { pontos ou mais em dor nos músculos do pescoço } \\
\text { e ombros e dor nos braços, e continuidade das } \\
\text { queixas durante a jornada) e o nível de fadiga } \\
\text { (intensa quando } 6 \text { ou } 7 \text { em alguns itens). }\end{array}$ \\
\hline $\begin{array}{l}\text { R.N.U.R / } \\
\text { Renault } \\
\text { Régie } \\
\text { Nationale } \\
\text { des Usines } \\
\text { Renault }\end{array}$ & $\begin{array}{l}\text { R.N.U.R. ou job profile method (método } \\
\text { de perfil de trabalho), com origem nos } \\
\text { anos 50, Renault, França, onde } \\
\text { especialistas procuravam soluções para } \\
\text { definir de forma objetiva as variáveis que } \\
\text { definem as condições de um posto de } \\
\text { trabalho (CALLEJÓN-FERRE, 2009). }\end{array}$ & $\begin{array}{l}\text { Analisa oito fatores através de vinte e três } \\
\text { critérios, pontuados em cinco níveis de satisfação } \\
\text { (onde } 1 \text { é muito satisfatório e } 5 \text { é muito perigoso). }\end{array}$ \\
\hline
\end{tabular}

Revista Produção Online. Florianópolis, SC, v. 18, n. 2, p. 665-690, 2018. 
Quadro 1 - Métodos/ferramentas ergonômicas para avaliação de riscos posturais e posto de trabalho (Conclusão)

\begin{tabular}{|c|c|c|}
\hline \multicolumn{3}{|c|}{ FERRAMENTAS DE AVALIAÇÃO PARA RISCOS POSTURAIS E POSTO DE TRABALHO } \\
\hline Método & Definições & Procedimentos \\
\hline \multirow[t]{2}{*}{ REBA } & $\begin{array}{l}\text { É derivado dos métodos de avaliação } \\
\text { postural RULA e OWAS (CARDOSO JR, } \\
\text { 2006). }\end{array}$ & \multirow{2}{*}{$\begin{array}{l}\text { Estabelece uma tabela relacionada ao Fator de } \\
\text { "Pega", onde são estabelecidos cinco níveis de } \\
\text { ação (ao invés dos quatro propostos no RULA). } \\
\text { Avalia o nível do risco, de muito baixo a muito alto } \\
\text { e indica a ação da investigação, de não } \\
\text { necessária à necessária e urgente. }\end{array}$} \\
\hline & $\begin{array}{l}\text { É uma ferramenta de análise de posturas } \\
\text { de corpo inteiro desenvolvido para avaliar } \\
\text { posturas de trabalho imprevisíveis } \\
\text { (GUIMARÃES, 2004). }\end{array}$ & \\
\hline $\begin{array}{l}\text { ROSA - } \\
\text { Rapid Office } \\
\text { Strains } \\
\text { Assessment }\end{array}$ & $\begin{array}{l}\text { Foi criado com base nas posturas } \\
\text { descritas nas orientações da CSA } \\
\text { (Canadian Standarts Association) e da } \\
\text { CCOHS (Centro Canadense de Saúde } \\
\text { Ocupacional e Segurança), onde } \\
\text { especialistas chegaram a um consenso } \\
\text { sobre a configuração da estação de } \\
\text { trabalho adequada (SONNE et al., 2012). }\end{array}$ & $\begin{array}{l}\text { Os fatores de risco no uso do computador foram } \\
\text { identificados, diagramados e agrupados nas } \\
\text { seguintes áreas: cadeira, monitores, telefone, } \\
\text { teclado e mouse. Uma pontuação foi atribuída, } \\
\text { variando de } 1 \text { a } 10 \text { (quanto maior a pontuação, } \\
\text { maior o desconforto). Em testes realizados por } \\
\text { Sonne et al. (2012), este método provou ser } \\
\text { eficaz e confiável para a identificação de fatores } \\
\text { de desconforto no uso do computador. }\end{array}$ \\
\hline \multirow[t]{2}{*}{$\begin{array}{l}\text { RULA - } \\
\text { Rapid Upper } \\
\text { Limb } \\
\text { Assessment }\end{array}$} & $\begin{array}{l}\text { Método de observação rápida para } \\
\text { análise postural, desenvolvido pelos Prof. } \\
\text { McAtammey e Corlett, da Universidade } \\
\text { de Ohio, para investigações ergonômicas } \\
\text { de postos de trabalho onde é possível } \\
\text { desenvolver lesões por esforços } \\
\text { repetitivos em membros superiores } \\
\text { (DOCKRELL, 2012). }\end{array}$ & \multirow[t]{2}{*}{$\begin{array}{l}\text { Na prática, utiliza-se de figuras de diferentes } \\
\text { posturas corporais, que recebem um valor } \\
\text { numérico que indica o grau de intervenção } \\
\text { necessário. Essa pontuação vai de } 1 \text { a } 7 \text {, com } \\
\text { níveis de ação de } 1 \text { a } 4 \text {, onde o nível } 1 \text { é postura } \\
\text { aceitável, e } 4 \text { sugere mudanças imediatas. }\end{array}$} \\
\hline & $\begin{array}{l}\text { O RULA baseia-se na metodologia } \\
\text { OWAS, onde as posturas adotadas são } \\
\text { representadas através de escores, que } \\
\text { associados a critérios biomecânicos e de } \\
\text { função muscular classificam a postura de } \\
\text { acordo com a carga (BARROS et al., } \\
\text { 2014). }\end{array}$ & \\
\hline $\begin{array}{l}\text { Suzzane } \\
\text { Rodgers }\end{array}$ & $\begin{array}{l}\text { Quantificação numérica, com pontuação } \\
\text { indicativa de risco da ocorrência de } \\
\text { LER/DORT, para os diversos } \\
\text { seguimentos corpóreos, como os } \\
\text { punhos, pescoço, ombros, cotovelos, } \\
\text { tronco, mãos e membros inferiores } \\
\text { (GUIMARÃES, 2004). }\end{array}$ & $\begin{array}{l}\text { Avalia o nível de esforço em baixo (1), moderado } \\
\text { (2) e pesado (3); o tempo de esforço de } 0 \text { a } 6 \\
\text { segundos (1), } 6 \text { a } 20 \text { (2), } 20 \text { a } 30 \text { (3) e maior que } \\
30 \text { (4); e o número de esforços por minuto de } 0 \text { a } \\
1 \text { minuto (1), } 1 \text { a } 5 \text { minutos (2), } 5 \text { a } 15 \text { minutos (3) } \\
\text { e maior que } 15 \text { minutos (4). Essa avaliação } \\
\text { contempla os segmentos do pescoço, ombros, } \\
\text { tronco, braços, punho, mão e dedos, pernas, } \\
\text { joelhos, tornozelos, pés e dedos. }\end{array}$ \\
\hline \multirow[t]{2}{*}{ ERGO/IBV } & $\begin{array}{l}\text { Desenvolvido pelo Instituto de } \\
\text { Biomecânica de Valência - Espanha, } \\
\text { avalia os riscos laborais associados à } \\
\text { carga física (COSTA, 2011). }\end{array}$ & \multirow[t]{2}{*}{$\begin{array}{l}\text { Classifica os riscos laborais associados à carga } \\
\text { física em quatro níveis, de ergonomicamente } \\
\text { aceitável (nível 1) à prioridade de investigação } \\
\text { (nível 4) (COSTA, 2011). }\end{array}$} \\
\hline & $\begin{array}{l}\text { Permite analisar tarefas repetitivas dos } \\
\text { membros superiores com ciclos de } \\
\text { trabalho claramente definidos, a fim de } \\
\text { avaliar o risco de lesão } \\
\text { musculoesquelética (INSHT, 2009). }\end{array}$ & \\
\hline
\end{tabular}

Fonte: Elaborado pelo autor a partir de múltiplas fontes 
Quadro 2- Métodos/ferramentas ergonômicas para avaliação de carga física

(continua) FERRAMENTAS PARA AVALIAÇÃO DA CARGA FÍSICA

\begin{tabular}{|c|c|c|}
\hline Método & Definições & Procedimentos \\
\hline $\begin{array}{l}\text { NIOSH - } \\
\text { National } \\
\text { Institute of } \\
\text { Occupa- } \\
\text { tional Safety } \\
\text { and Health }\end{array}$ & $\begin{array}{l}\text { Método que avalia a carga levantada } \\
\text { pelos trabalhadores sem causar lesões, } \\
\text { foi concebido em 1981, e revisado ao } \\
\text { longo dos anos, tornando-se uma } \\
\text { equação que fornece métodos para a } \\
\text { avaliação de tarefas de levantamento } \\
\text { assimétrico de cargas e levantamento de } \\
\text { objetos com pegas não ideias com } \\
\text { ambas as mãos (ERGO, 2006). }\end{array}$ & $\begin{array}{l}\text { O NIOSH considera: } \\
\text { LPR: Limite de Peso Recomendado, ou seja, o } \\
\text { peso da carga suportada por trabalhadores sadios } \\
\text { num período de tempo, sob determinadas } \\
\text { condições, sem aumentar o risco de lombalgia. } \\
\text { Sua fórmula considera a distância horizontal entre } \\
\text { o indivíduo e a carga, a distância vertical entre } \\
\text { ambos, o deslocamento, o ângulo de assimetria, a } \\
\text { frequência média de levantamentos e a qualidade } \\
\text { da pega. } \\
\text { IL: Índice de Levantamento, fornece uma } \\
\text { estimativa do nível de estresse físico em } \\
\text { levantamento manual; } \\
\text { Terminologia e Definições de Dados: Define os } \\
\text { parâmetros do levantamento, peso da carga, } \\
\text { distância horizontal, altura vertical, altura vertical } \\
\text { percorrida, ângulo de assimetria, posição do } \\
\text { corpo, frequência e duração do levantamento, } \\
\text { classificação da pega e controle motor } \\
\text { significativo. }\end{array}$ \\
\hline $\begin{array}{l}\text { INSHT (Inst. } \\
\text { Nac. } \\
\text { Seguridad } \\
\text { Higiene em } \\
\text { el Trabajo }\end{array}$ & $\begin{array}{l}\text { É um método de avaliação de riscos na } \\
\text { MMC (Manipulação Manual de Cargas) } \\
(\text { (CCOO, 2015). }\end{array}$ & $\begin{array}{l}\text { Considera severidade do dano (ligeiramente } \\
\text { prejudicial, prejudicial, extremamente prejudicial) } \\
\text { e a probabilidade de ocorrência do dano (alta, } \\
\text { média, baixa). Entretanto, por ser de } \\
\text { aplicabilidade individual e subjetiva, recomenda- } \\
\text { se combinar os resultados técnicos com as } \\
\text { condições de trabalho e a opinião dos } \\
\text { trabalhadores. }\end{array}$ \\
\hline $\begin{array}{l}\text { JSI - JOB } \\
\text { STRAIN } \\
\text { INDEX ou SI } \\
\text { ou } \\
\text { MOORE } \\
\text { AND GARG }\end{array}$ & $\begin{array}{l}\text { O método JSI, também conhecido como } \\
\text { critério semi-quantitativo, criado em } 1995 \\
\text { por Moore \& Garg, quantifica a exposição } \\
\text { a fatores de risco MSD (desordens } \\
\text { musculoesqueléticas) para as mãos e } \\
\text { pulsos, fornecendo um índice que leva } \\
\text { em conta o nível de percepção de } \\
\text { esforço, tempo de esforço como uma } \\
\text { percentagem do tempo de ciclo, número } \\
\text { de esforços, mão e postura de pulso, } \\
\text { velocidade de trabalho e tempo de } \\
\text { deslocamento (CHIASSON, 2012). } \\
\text { É um aprimoramento do método de } \\
\text { Rodgers, feita com base em vídeos. Se } \\
\text { propõe a avaliar mãos e pulso. Sugere a } \\
\text { avaliação de } 6 \text { fatores, dividindo-a em } \\
\text { hemicorpo direito e esquerdo } \\
\text { (GUIMARÃES, 2004). }\end{array}$ & $\begin{array}{l}\text { Utiliza como parâmetros a intensidade, duração e } \\
\text { frequência do esforço, postura, ritmo e duração do } \\
\text { trabalho e avalia o índice de sobrecarga para os } \\
\text { membros superiores, sendo baseado no campo } \\
\text { da fisiologia, biomecânica e epidemiologia, e vem } \\
\text { sendo amplamente aplicado na indústria. Vários } \\
\text { estudos validam a ferramenta, em termos de } \\
\text { conteúdo relevante e consistente, validade } \\
\text { preditiva (identifica corretamente um perigo), e } \\
\text { validade externa (eficaz em diferentes cenários) } \\
\text { (CABEÇAS, 2007). }\end{array}$ \\
\hline
\end{tabular}


Quadro 2- Métodos/ferramentas ergonômicas para avaliação de carga física

(Conclusão) FERRAMENTAS PARA AVALIAÇÃO DA CARGA FÍSICA

\begin{tabular}{|c|c|c|}
\hline Método & Definições & Procedimentos \\
\hline \multirow[t]{2}{*}{$\begin{array}{l}\text { KIM - Key } \\
\text { Indicator Method }\end{array}$} & $\begin{array}{l}\text { É utilizado para avaliar tarefas que } \\
\text { envolvem operações de movimentação } \\
\text { manual (DOUWES, KRAKER, 2014). }\end{array}$ & $\begin{array}{l}\text { Segundo o ETUI - Instituto Sindical Europeu } \\
\text { (2014), duas ferramentas KIM foram } \\
\text { desenvolvidas para a avaliação dos riscos no } \\
\text { caso de tarefas de: levantar, manter, colocar; e } \\
\text { empurrar ou puxar uma carga. Considera o } \\
\text { número de levantamentos ou transporte de } \\
\text { carga por dia de trabalho, a sua duração total no } \\
\text { dia (<5s) e a distância total percorrida no } \\
\text { transporte da carga, o que gera uma pontuação } \\
\text { de duração de } 1 \text { a } 10 \text {. }\end{array}$ \\
\hline & $\begin{array}{l}\text { Este método realiza a descrição da } \\
\text { tarefa e a avalição separadamente, } \\
\text { quando os itens chaves são pontuados } \\
\text { sem necessitar de medições exatas } \\
\text { (imprecisão calculada) (OSHA - } \\
\text { Agência Europeia para a Segurança e } \\
\text { Saúde no Trabalho, 2015). }\end{array}$ & $\begin{array}{l}\text { A análise de risco é baseada num modelo de } \\
\text { dose (duração multiplicada pela intensidade). }\end{array}$ \\
\hline
\end{tabular}

Fonte: Elaborado pelo autor a partir de múltiplas fontes

Quadro 3 - Métodos/ferramentas ergonômicas para avaliação do conforto térmico FERRAMENTA PARA AVALIAÇÃO DO CONFORTO TÉRMICO

\begin{tabular}{|l|l|l|}
\hline Método & Definições & Procedimentos \\
\hline FANGER & $\begin{array}{l}\text { O modelo de conforto térmico de Fanger (anos } \\
\text { 70), é um dos modelos mais adiantados e } \\
\text { ainda o mais extensamente usado em predizer } \\
\text { a sensação térmica (ALAHMER, 2012). }\end{array}$ & $\begin{array}{l}\text { É baseado em dois índices: } \\
\text { PMV (voto médio estimado, de um grande grupo } \\
\text { de pessoas sujeitas a um mesmo ambiente } \\
\text { térmico) e PPD (percentagem de pessoas } \\
\text { insatisfeitas, calculado sobre o valor de PMV e } \\
\text { na escala de ASHRAE) (TALAIA, 2013). }\end{array}$ \\
\cline { 2 - 3 } & $\begin{array}{l}\text { O conforto térmico é condição essencial para } \\
\text { a saúde, segurança e produtividade do } \\
\text { trabalhador (OLIVEIRA et al., 2010). }\end{array}$ & $\begin{array}{l}\text { É baseado em um contrapeso de energia do } \\
\text { corpo humano, considerado como um sistema } \\
\text { termodinâmico que troca calor com o ambiente } \\
\text { externo. }\end{array}$ \\
\hline
\end{tabular}

Fonte: Elaborado pelo autor a partir de múltiplas fontes 
Quadro 4 - Métodos/ferramentas ergonômicas para avaliação de carga Mental

\section{FERRAMENTAS PARA AVALIAÇÃO DA CARGA MENTAL}

\begin{tabular}{|c|c|c|}
\hline Método & Definições & Procedimentos \\
\hline $\begin{array}{l}\text { NASA-TLX - } \\
\text { Task Load } \\
\text { Index - Índice } \\
\text { Carga Tarefa }\end{array}$ & $\begin{array}{l}\text { Foi desenvolvido no laboratório de } \\
\text { pesquisas da NASA, em 1987. Tem } \\
\text { como objetivo avaliar a carga mental do } \\
\text { trabalhador, observando a duração da } \\
\text { jornada, dor, sexo, idade, nível de } \\
\text { escolaridade e tempo na função. É um } \\
\text { procedimento de taxa multidimensional } \\
\text { (CARDOSO, 2012). }\end{array}$ & $\begin{array}{l}\text { Provê uma pontuação global da Carga de } \\
\text { Trabalho baseada em uma média ponderada de } \\
\text { avaliações em seis subescalas: exigência } \\
\text { (demanda) mental, física, temporal, nível de } \\
\text { realização, de esforço e de frustração. Em estudo } \\
\text { de Cardoso (2012), este método apresentou-se } \\
\text { mais indicado para avaliar as dimensões } \\
\text { associadas à carga mental e para comparar os } \\
\text { resultados de diferentes sujeitos para uma mesma } \\
\text { tarefa (em comparação ao método SWAT). }\end{array}$ \\
\hline SWAT & $\begin{array}{l}\text { Os métodos mais indicados para } \\
\text { avaliação de carga mental são o } \\
\text { NASA-TLX e SWAT (Subjective } \\
\text { Workload Assessment Technice), } \\
\text { sendo que este último foi desenvolvido } \\
\text { pelo grupo de pesquisa de Reid, } \\
\text { Eggemeier e Shingledecker (1982). Em } \\
\text { estudo realizado para revisar este } \\
\text { método, observou-se que o mesmo é } \\
\text { mais sensível para avaliar a carga } \\
\text { mental de trabalho e a comparação de } \\
\text { desempenho do trabalhador em } \\
\text { diferentes atividades. Sua aplicação, } \\
\text { por contemplar maior número de } \\
\text { combinações (peso das dimensões), foi } \\
\text { apontada como cansativa (CARDOSO, } \\
\text { 2012). }\end{array}$ & $\begin{array}{l}\text { Utiliza técnica de medida conjunta que considera } \\
\text { que a carga mental de uma tarefa é medida em } \\
\text { três dimensões: tempo, esforço mental e estresse. } \\
\text { Essas dimensões são avaliadas por uma escala } \\
\text { de } 3 \text { pontos para: normalmente, ás vezes ou } \\
\text { raramente sobra tempo; pouca, moderada e } \\
\text { elevada exigência mental; e baixo, moderado e } \\
\text { elevado nível de estresse. Este método é aplicado } \\
\text { em duas fases: obtenção da escala de carga } \\
\text { mental de trabalho e avaliação dos níveis de } \\
\text { carga mental. }\end{array}$ \\
\hline
\end{tabular}

Fonte: Elaborado pelo autor a partir de múltiplas fontes

Quadro 5 - Métodos/ferramentas ergonômicas para avaliação macro ergonômica

(Continua) FERRAMENTAS PARA AVALIAÇÃO MACRO ERGONÔMICA

\begin{tabular}{|c|c|c|}
\hline Método & Definições & Procedimentos \\
\hline \multirow[t]{2}{*}{$\begin{array}{l}\text { AET-Análise } \\
\text { Ergonômica } \\
\text { do Trabalho }\end{array}$} & $\begin{array}{l}\text { Visa aplicar os conhecimentos da } \\
\text { ergonomia para analisar, diagnosticar } \\
\text { e corrigir uma situação real de } \\
\text { trabalho, sendo um exemplo de } \\
\text { ergonomia de correção (IIDA, 2005). }\end{array}$ & $\begin{array}{l}\text { Análise da Demanda: descrição de problemas que } \\
\text { demandam uma ação ergonômica; } \\
\text { Análise da Tarefa: busca as discrepâncias entre o } \\
\text { que é prescrito e o que é executado; } \\
\text { Análise da Atividade: comportamento do trabalhador } \\
\text { na realização de uma tarefa; } \\
\text { Diagnóstico: descobrir as causas que provocam o } \\
\text { problema; } \\
\text { Recomendações: o que deve ser feito para resolver o } \\
\text { problema. } \\
\text { Considera o posto de trabalho, as pressões, a carga } \\
\text { cognitiva, a densidade e a organização do trabalho, o } \\
\text { modo operatório, os ritmos e as posturas. }\end{array}$ \\
\hline & $\begin{array}{l}\text { Metodologia própria de intervenção - } \\
\text { a Análise Ergonômica do Trabalho, } \\
\text { cujo objetivo é examinar a } \\
\text { complexidade sem colocar em prova } \\
\text { um modelo pré-selecionado } \\
\text { (CARVALHO, 2014). }\end{array}$ & $\begin{array}{l}\text { Utiliza técnicas objetivas (diretas): registro de } \\
\text { atividades ao longo de um período, observadas ou } \\
\text { gravadas; ou subjetivas (indiretas): questionários, } \\
\text { checklists e entrevistas. (IIDA, 2005). }\end{array}$ \\
\hline LEST & $\begin{array}{l}\text { É um método biomecânico } \\
\text { desenvolvido na França, em 1978, } \\
\text { pelo Laboratório de Economia e } \\
\text { Sociologia do Trabalho da C.N.R.S } \\
\text { (Centre National de la Recherche } \\
\text { Scientifique) (LIMA, 2003; FALCÃO, } \\
\text { 2007). }\end{array}$ & $\begin{array}{l}\text { Considera dezesseis variáveis agrupadas em cinco } \\
\text { aspectos (dimensões): ambiente físico, carga física, } \\
\text { carga mental, aspectos psicossociais e tempo de } \\
\text { trabalho; sendo de simples aplicação. Considera, } \\
\text { num primeiro momento, as variáveis quantitativas (ex: } \\
\text { níveis de temperatura, ruído), e posteriormente as } \\
\text { variáveis qualitativas e pontos de vista do trabalhador } \\
\text { (carga mental e aspectos psicossociais). }\end{array}$ \\
\hline
\end{tabular}

Revista Produção Online. Florianópolis, SC, v. 18, n. 2, p. 665-690, 2018. 
Quadro 5 - Métodos/ferramentas ergonômicas para avaliação macro ergonômica

(Conclusão)

\begin{tabular}{|c|c|c|}
\hline \multicolumn{3}{|c|}{ FERRAMENTAS PARA AVALIAÇÃO MACRO ERGONÔMICA } \\
\hline Método & Definições & Procedimentos \\
\hline & $\begin{array}{l}\text { Este método avalia as condições } \\
\text { psicossociais ergonômicas dos postos de } \\
\text { trabalho (CALLEJóN-FERRE, 2009). }\end{array}$ & \\
\hline & $\begin{array}{l}\text { Foi desenvolvido para avaliar os postos de } \\
\text { trabalho permanentes no setor industrial, } \\
\text { não podendo ser aplicado a qualquer tipo de } \\
\text { trabalho (somente em ambientes com } \\
\text { características constantes) (DIEGO-MÁs; } \\
\text { CUESTA, 2015). }\end{array}$ & \\
\hline MAPFRE & $\begin{array}{l}\text { Foi desenvolvido na Espanha, na década de } \\
80, \text { com base nos métodos LEST e R.N.U.R. } \\
\text { É também chamado de método de análise } \\
\text { ergonômica de posto de trabalho, e sua } \\
\text { proposta é de avaliação ergonômica } \\
\text { simplificada, partindo de uma análise geral } \\
\text { para então abordar os aspectos } \\
\text { considerados como negativos. A aplicação } \\
\text { do método divide-se em } 3 \text { etapas: descritiva } \\
\text { (descrição do posto de trabalho), avaliativa } \\
\text { (seleção das variáveis consideradas na } \\
\text { avaliação) e corretiva (correções propostas e } \\
\text { seus benefícios) (LIMA, 2003). }\end{array}$ & $\begin{array}{l}\text { Adota como critérios de avaliação as as } \\
\text { características de: posto de trabalho (ambiente, } \\
\text { mobiliário, movimentos, instrumentos, etc.); a } \\
\text { intensidade, forma e instrumentos na atividade } \\
\text { física requerida para a tarefa (carga física postural } \\
\text { estática e dinâmica); a carga sensorial (atenção, } \\
\text { recepção de informação e tomada de decisão); a } \\
\text { carga mental quantitativa, qualitativa (muito difícil) } \\
\text { e infracarga (fácil demais); a autonomia e } \\
\text { decisões (iniciativa); monotonia e repetitividade; a } \\
\text { comunicação e as relações; os turnos, horários e } \\
\text { pausas; os riscos de acidente; o ruído; o ambiente } \\
\text { térmico; a iluminação; e as radiações. }\end{array}$ \\
\hline
\end{tabular}

Fonte: Elaborado pelo autor a partir de múltiplas fontes

\section{MATERIAIS E MÉTODOS}

Esta pesquisa é de caráter qualitativo, envolvendo dados quantitativos secundários que corroboram para a sua construção, realizada sob os preceitos do método de Estudo de Campo ou pesquisa de campo (NAKANO, 2012), onde um estudo teórico é conduzido através de discussões conceituais a partir da literatura. A Figura 1 descreve os passos metodológicos.

Figura 1 - Delineamento da pesquisa

\begin{tabular}{|c|c|c|}
\hline $\begin{array}{l}\text { Etapa 1: Dados sobre publicações } \\
\text { em métodos ergonômicos }\end{array}$ & $\begin{array}{l}\text { Etapa 2: Percepção e uso dos } \\
\text { métodos pelos especialistas }\end{array}$ & Etapa 3: Análise dos dados \\
\hline $\begin{array}{l}\text { Pesquisar métodos e definir } \\
\text { palavras-chave ( } 24 \text { métodos } \\
\text { ergonômicos encontrados) }\end{array}$ & $\begin{array}{l}\text { Elaborar questionário sobre os } \\
24 \text { métodos encontrados }\end{array}$ & \multirow[t]{2}{*}{$\begin{array}{c}\text { Analisar dados de publicação no } \\
\text { software statgraphics, em busca de } \\
\text { frequência e tendências }\end{array}$} \\
\hline$\downarrow$ & $\downarrow$ & \\
\hline \multirow{4}{*}{$\begin{array}{l}\text { Pesquisar palavras-chave na } \\
\text { base ScienceDirect, de } 2004 \text { a } \\
2014 \text {, e gerenciar as } \\
\text { referências no Mendeley } \\
\text { (2507 referências) }\end{array}$} & \multirow{4}{*}{$\begin{array}{c}\text { Aplicar questionário à } 5 \\
\text { especialistas que já haviam } \\
\text { aplicado pelo menos um dos } \\
24 \text { métodos, com foco na } \\
\text { percepção e uso }\end{array}$} & \multirow{2}{*}{$\begin{array}{c}\downarrow \\
\text { Analisar as respostas ao } \\
\text { questionário, mapeando as } \\
\text { vantagens, desvantagens e } \\
\text { recomendaçóes sobre métodos } \\
\text { de avaliação ergonômica }\end{array}$} \\
\hline & & \\
\hline & & $\downarrow$ \\
\hline & & $\begin{array}{l}\text { Discussões contrapondo os } \\
\text { métodos mais incidentes em } \\
\text { publicações os métodos mais } \\
\text { utilizados pelos especialistas, e as } \\
\text { recomendações contidas na } \\
\text { literatura }\end{array}$ \\
\hline
\end{tabular}

Fonte: Elaborado pelo autor a partir de múltiplas fontes 
Para definir os parâmetros de consulta à base de dados científicos, os métodos foram selecionados a partir de revisão da literatura em livros, artigos, monografias, websites de ergonomia, normas, softwares de avaliação ergonômica, e encontrados ou sugeridos ao acaso. Para definição dos métodos, buscaram-se conceitos e definições da área, quando possível, em artigos científicos, e em manuais técnicos, quando de um método pouco difundido, e também o conceito gramatical.

É importante ressaltar que o assunto não foi esgotado; como os compêndios sobre métodos e ferramentas de avaliação ergonômica são parciais ou descontinuados, e no intuito de viabilizar este estudo, definiram-se os seguintes critérios de parada: a convergência da pesquisa (após os 20 primeiros métodos encontrados, os resultados tornaram-se semelhantes, apresentando uma tendência de convergir naquele grupo de métodos); a incidência de repetição (os métodos mais "populares" tornaram-se frequentes); os "não métodos" (o número de normas, técnicas ou índices tornou-se mais frequente); e o baixo índice de métodos diferentes (o surgimento de métodos diferentes aos selecionados tornou-se pouco frequente ao longo do período estudado). Ou seja, ao perceber que alguns métodos ergonômicos, tais como NASA-TLX, NIOSH, fanger, OWAS, RULA, entre outros, se repetiam a cada resultado, e métodos diferentes dos já encontrados (MAPFRE, LEST, KIM, etc.) demoravam cada vez mais a aparecer, até que, após a análise de diversos documentos e pesquisas em buscador da internet, nenhum método diferente do já encontrado ocorreu, optou-se por encerrar as buscas e iniciar a revisão de literatura.

Após a revisão de literatura, e a definição de método ergonômico, realizouse uma categorização, chegando a vinte e quatro métodos ergonômicos, os quais foram utilizados na pesquisa de publicações. Para a pesquisa na base de dados ScienceDirect, utilizou-se o sistema de buscas dessa base, aplicando os seguintes filtros de pesquisa avançada: aba Journals, palavra-chave em todos os campos, na área de Engineering, documentos do tipo article and review article, de 2004 até o presente, totalizando 2.507 referências. Quando o resultado da busca por palavra simples não representava o assunto pesquisado, utilizou-se o operador lógico AND, associando uma palavra-chave secundária que descrevia o método. Ex: "rula" AND "rapid upper limb assessment". Após a pesquisa no ScienceDirect, os dados foram 
exportados em formato .RIS, e então importados no software Mendeley Desktop, um software gratuito para gerenciamento de Referências Bibliográficas. Esses dados foram organizados por métodos, e precisavam ser exportados para o Excel para tratamento estatístico. Os dados foram então exportados para o software JabRef 2.0 no formato .RIS, exportados novamente em formato .csv e finalmente importados no Excel, cuja configuração dos parâmetros foi: tipo de campo delimitado, origem do arquivo UNICODE UTF-8 e delimitadores tabulação e vírgula. Esse procedimento foi necessário pois não foi possível importar os dados de forma direta do Mendeley para o Excel, sendo que muitos pesquisadores ainda realizam esse procedimento manualmente.

A primeira análise dos dados utilizou estatística descritiva, após executadas as etapas de seleção e filtro das publicações. Os resultados foram apresentados em busca da tendência ao longo dos anos, de especial interesse nesse trabalho. Para tal foi feito ajuste de séries temporais, através de modelos de ajuste exponencial, incluindo-se o modelo linear pela análise gráfica prévia dos dados. Após isso o melhor modelo foi escolhido pelo critério de informação de Akaike (AIC) (AKAIKE, 1974). Recentemente Snyder e Ord (2009) mostraram que esse critério é adequado para quaisquer modelos de séries temporais. Então uma previsão para 2015 e 2016 apresenta as tendências nos próximos 02 anos. O próximo passo consistiu na elaboração de questionário sobre uso dos métodos e aplicação a cinco especialistas (ergonomista, pesquisador, médico do trabalho, engenheiro do trabalho, engenheiro de segurança e fisioterapeuta), e análise das respostas. Por fim, realizou-se uma análise crítica sobre os métodos mais incidentes, confrontando as recomendações contidas na literatura com as percepções dos especialistas, em busca de perspectivas para novas abordagens.

$\mathrm{Na}$ etapa de consulta aos especialistas, visando atingir profissionais de diferentes cidades, a entrevista foi aplicada em forma de questionário online composto por 15 questões. Elaborou-se um roteiro para entrevista estruturada, utilizando a ferramenta Google Docs, com o objetivo de perceber a opinião dos especialistas em relação aos métodos: quais já utilizaram, as experiências com o método, aplicações, e que outros métodos, diferentes dos listados na pesquisa, são utilizados. As questões foram construídas de modo que: de 1 a 3 fornecesse o perfil do profissional; a questão 4 listou os métodos e mediu o nível de satisfação no uso 
(escala), vantagens e desvantagens (questão aberta); de 5 a 13, as questões pediam recomendações de métodos para cada tipo de aplicação; a questão 14 argumentava sobre o uso de softwares, e a última questão era de conteúdo livre. Para medir a satisfação no uso dos métodos (questão 4), aplicou-se escala likert adaptada, de 1 a 5, de insatisfeito a muito satisfeito, onde os pontos 2, 3 e 4 indicam uma intensidade entre os extremos, sem nomenclatura, uma vez que o critério neutro ou intermediário comumente utilizado como "indiferente" pode gerar dúvidas quanto ao seu significado por parte dos respondentes e pode prejudicar a interpretação dos resultados. Num pré-teste, a primeira versão do questionário foi respondida por um pesquisador ergonomista (20 anos de experiência em Segurança do Trabalho, há 15 em Ergonomia), o qual identificou alguns problemas na estrutura do questionário, e também sugeriu algumas melhorias. O questionário foi adaptado, e também reorganizado, e novamente aplicado ao ergonomista, que respondeu e validou a ferramenta. Após a validação, realizou-se um teste piloto, cuja aplicação foi realizada com orientação de um pesquisador a uma fisioterapeuta, para identificar problemas e esclarecer dúvidas. Após a validação e o teste piloto, as outras aplicações do questionário foram realizadas via e-mail e outras formas virtuais de contato (formulários, currículo lattes, redes sociais). O questionário foi enviado a 10 especialistas; porém, como a taxa de resposta foi de apenas $20 \%$, o questionário foi enviado a outros 15 especialistas. Ao final, foram obtidas 5 respostas de especialistas, as quais fundamentaram a revisão crítica dos métodos (seção 3.2). Os respondentes, distribuídos em diferentes estados, possuem formação e afiliação em diferentes escolas do pensamento.

\section{RESULTADOS}

\subsection{Pesquisa dos métodos na base ScienceDirect e análise dos dados}

A pesquisa nas bases retornou 2.507 registros, os quais foram organizados por título, periódico, método relacionado, ano, mês e país de publicação. A Tabela 1 lista 23 dos 24 métodos ergonômicos (o método Checklist de Couto obteve frequência igual a 0) para os parâmetros de entrada, a fim de identificar quais os mais publicados nos últimos dez anos dentro da amostra. Na seção Resultados, os 
métodos mais comuns (frequência superior a 2\%) serão analisados em contraponto com a opinião de especialistas.

Após a identificação dos métodos mais frequentes nas referências coletadas, realizou-se uma análise de tendência do período 2004-2014 em publicações envolvendo métodos ergonômicos, assim como para os três métodos mais utilizados (NIOSH, fanger e NASA-TLX) (Figuras 2, 3, 4 e 5).

Tabela 1 - Tabela de frequência para os métodos ergonômicos

\begin{tabular}{llll}
\hline Class & Método & Frequência & Frequência relativa \\
\hline 1 & NIOSH & 997 & $39,77 \%$ \\
2 & Fanger & 824 & $32,87 \%$ \\
3 & NASA-TLX & 194 & $7,74 \%$ \\
4 & OWAS & 89 & $3,55 \%$ \\
5 & REBA & 69 & $2,75 \%$ \\
6 & RULA & 52 & $2,07 \%$ \\
7 & OCRA & 46 & $1,83 \%$ \\
8 & JSI & 45 & $1,79 \%$ \\
9 & QEC & 40 & $1,60 \%$ \\
10 & LUBA & 32 & $1,28 \%$ \\
11 & MAPFRE & 32 & $1,28 \%$ \\
12 & INSHT & 29 & $1,16 \%$ \\
13 & AET & 16 & $0,64 \%$ \\
14 & Ergo/IBV & 12 & $0,48 \%$ \\
15 & EWA & 5 & $0,20 \%$ \\
16 & KIM & 5 & $0,20 \%$ \\
17 & Questionário Bipolar & 5 & $0,20 \%$ \\
18 & Suzanne Rodgers & 5 & $0,20 \%$ \\
19 & SWAT & 5 & $0,20 \%$ \\
20 & ROSA & 2 & $0,08 \%$ \\
21 & R.N.U.R / Renault & 1 & $0,04 \%$ \\
22 & LEST & 1 & $0,04 \%$ \\
23 & OREGE & 1 & $0,04 \%$ \\
\hline
\end{tabular}

Fonte: Elaborado pelo autor

Figura 2 - Análise das publicações relacionadas aos métodos ergonômicos nos últimos dez anos e tendências. Comportamento linear, crescimento se mantém nos próximos dois anos

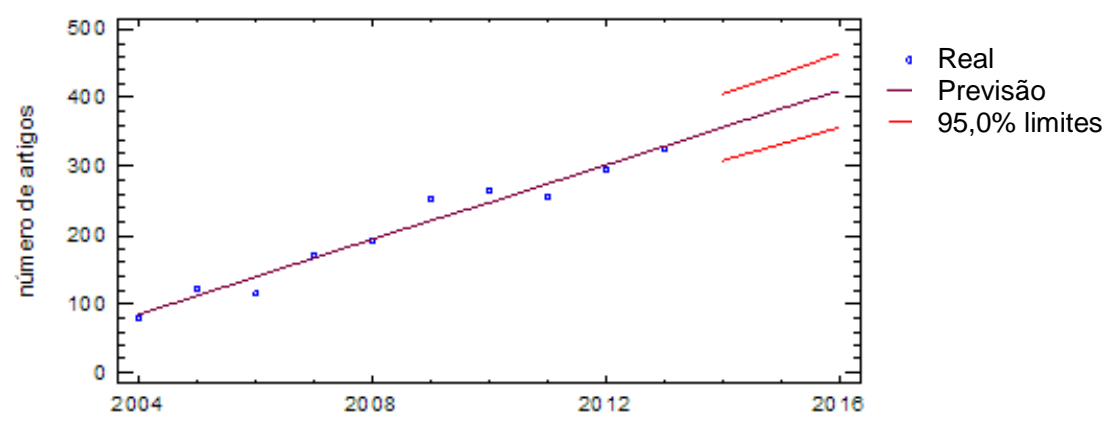


Figura 3 - Frequência de publicações associadas ao método de maior frequência: NIOSH. Comportamento linear, crescimento se mantém nos próximos dois anos

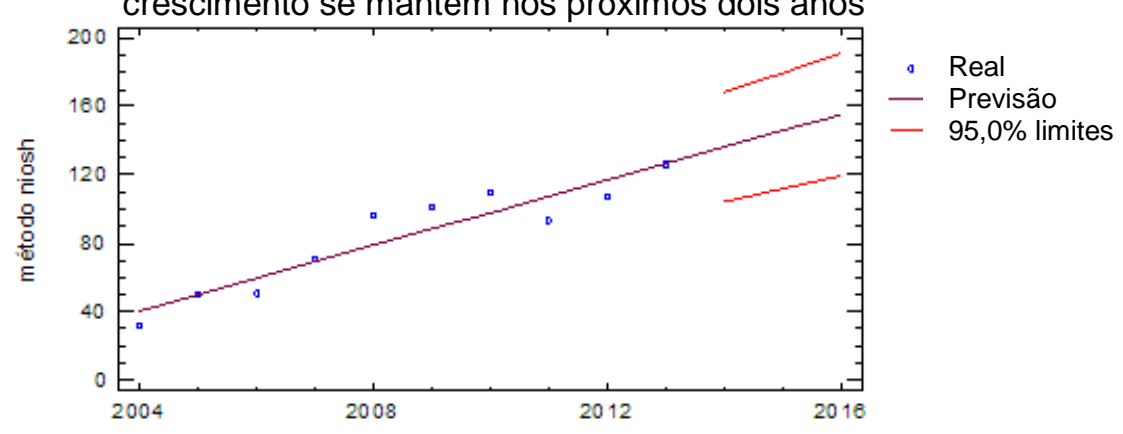

Figura 4 -Frequência de publicações associadas ao método de Fanger. Comportamento linear, crescimento se mantém nos próximos dois anos

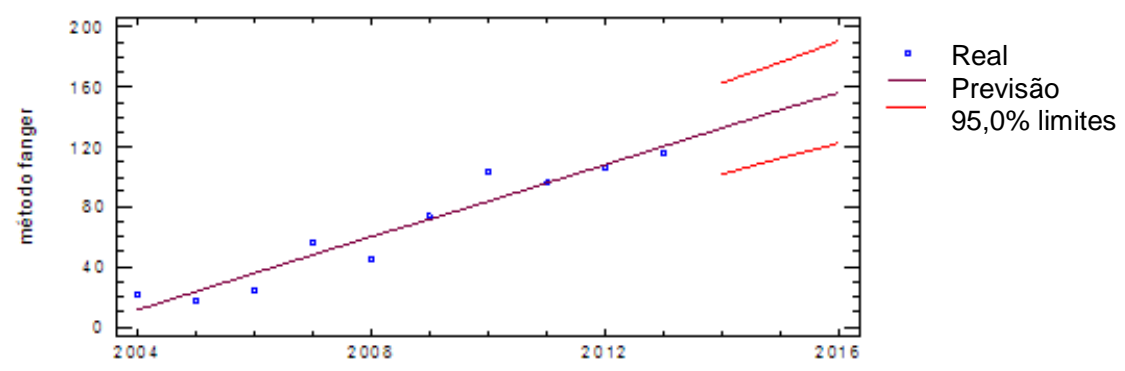

Figura 5 - Frequência de publicações associadas ao método de NASA-TLX. Comportamento linear, crescimento se mantém nos próximos dois anos

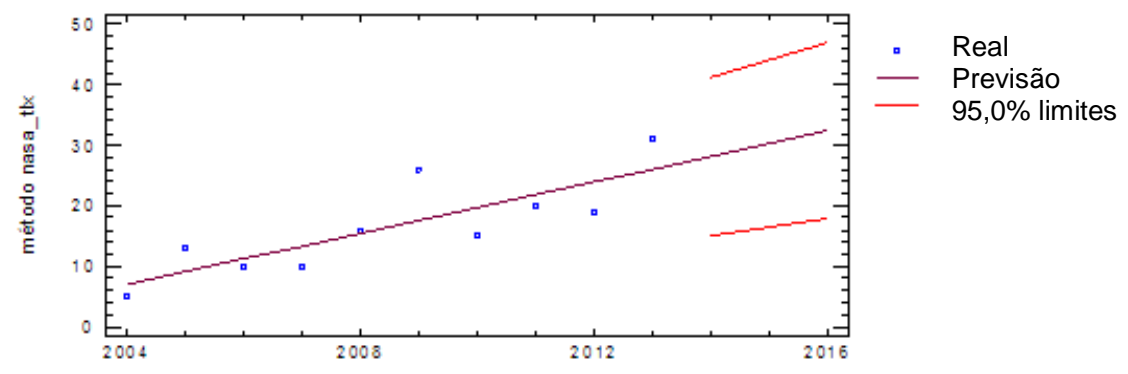

Após identificar os mais incidentes nas publicações, investigou-se o uso dos métodos junto aos especialistas no intuito de verificar os mais utilizados e as percepções de uso, e confrontar os resultados. 


\subsection{Elaboração e aplicação de questionário aos especialistas e análise das respostas}

A partir dos dados coletados por meio do questionário, foi possível identificar os métodos mais utilizados pelos especialistas e suas percepções em relação a eles, as vantagens e desvantagens dos métodos indicados, a fim de confrontar os apontamentos da literatura com a percepção dos profissionais, e então fundamentar a análise crítica desses métodos. O questionário foi respondido por cinco profissionais, os quais utilizam a ergonomia para diagnóstico, laudo, projetos e avaliação da atividade, e atuam como ergonomistas, engenheiros de segurança do trabalho, fisioterapeutas, pesquisador, professor e/ou designer de produtos.

Nenhum dos cinco profissionais investigados avaliou ou utilizou os seguintes métodos: Ergo/IBV, Fanger, INSHT, KIM, LEST, LUBA, MAPFRE, OREGE, QEC, RNUR/Renault, ROSA. Os fatores que podem ter colaborado para a não incidência desses métodos são: a localização geográfica (os métodos ergo/IBV e MAPFRE, por exemplo, são mais populares na Espanha), e a data de criação (o método LEST foi criado em 1978 e deu origem a outros métodos, portanto é utilizado de forma indireta). O método fanger, o segundo mais incidente na pesquisa às publicações, é muito frequente nas engenharias; entretanto, os profissionais de ergonomia entrevistados atuam principalmente na ergonomia de correção, justificando a falta de informações quanto ao método em especial. No Quadro 6 serão descritas as percepções dos profissionais em relação aos demais métodos ergonômicos contemplados neste artigo, onde "média" refere-se à média das notas atribuídas pelos especialistas ao método numa escala de 1-5, e "uso" refere-se à quantidade de profissionais, dentre os 5 entrevistados, que haviam usado o método. 
Quadro 6 - Análise crítica dos métodos de avaliação ergonômica: vantagens e desvantagens práticas

\begin{tabular}{|c|c|c|}
\hline Método & Análise crítica, vantagens e desvantagens & $\begin{array}{l}\text { 1- Insatisfeito a } \\
\text { 5- Muito Satisfeito }\end{array}$ \\
\hline AET & $\begin{array}{l}\text { Considerou-se como vantagens do método a análise da demanda, } \\
\text { atividade, condições ambientais, diagnóstico e caderno de encargos e } \\
\text { sugestões. Já as desvantagens citadas ressaltam ser um método não } \\
\text { específico, que precisa ser associado a outros métodos para realizar a } \\
\text { avaliação. Um dos profissionais informou utilizar a Intervenção } \\
\text { Ergonomizadora e a Análise Macroergonômica do Trabalho, em } \\
\text { substituição ao AET, devido à maior afinidade com os métodos e o } \\
\text { trabalho de pesquisa junto aos autores. Entende-se então, que a } \\
\text { Análise Ergonômica do Trabalho é um método de diagnóstico, que } \\
\text { poderia preceder a aplicação dos métodos específicos. }\end{array}$ & $\begin{array}{l}\text { Média: } 4 \\
\text { Uso: } 3 \text { de } 5\end{array}$ \\
\hline $\begin{array}{l}\text { Checklist } \\
\text { de Couto }\end{array}$ & $\begin{array}{l}\text { Dois profissionais questionaram a validade científica deste método. } \\
\text { Entretanto, citou-se como vantagem ser fácil e de rápida aplicação, } \\
\text { podendo ser utilizado como método descritivo dentro da análise. Como } \\
\text { desvantagens, apontou-se que o checklist não considera alguns } \\
\text { aspectos, o que o torna impreciso, produzindo resultados que não } \\
\text { representam a situação real. }\end{array}$ & $\begin{array}{l}\text { Média: } 2,7 \text { de } 5 \\
\text { Uso: } 3 \text { de } 5\end{array}$ \\
\hline EWA & $\begin{array}{l}\text { A vantagem deste método está em sua fácil utilização, e sua } \\
\text { desvantagem em ser restrito a algumas regiões do corpo. }\end{array}$ & $\begin{array}{l}\text { Média: } 4 \text { de } 5 \\
\text { Uso: } 1 \text { de } 5\end{array}$ \\
\hline JSI & Este método foi elogiado por ser simples e operacional. & $\begin{array}{l}\text { Média: } 5 \text { de } 5 \\
\text { Uso: } 1 \text { de } 5\end{array}$ \\
\hline $\begin{array}{l}\text { NASA- } \\
\text { TLX }\end{array}$ & $\begin{array}{l}\text { As vantagens apontadas foram a capacidade em realizar coleta de } \\
\text { dados gerais relativas à carga de trabalho mental sob a percepção } \\
\text { dos pesquisadores, e os resultados bem aprofundados. A } \\
\text { desvantagem está no difícil entendimento e interpretação por parte } \\
\text { dos respondentes. Já no quesito facilidade de aplicação, houve } \\
\text { contradições: enquanto um profissional achou o método difícil de } \\
\text { entender como aplicar e obter o diagnóstico, outro especialista diz } \\
\text { achar a ferramenta relativamente simples de aplicar. Dos } \\
\text { profissionais com opiniões divergentes, um é } \\
\text { fisioterapeuta/ergonomista e outro é engenheiro de segurança do } \\
\text { trabalho, levando a supor que perfis diferentes gerem percepções } \\
\text { diferentes. }\end{array}$ & $\begin{array}{l}\text { Média: } 4,3 \text { de } 5 \\
\text { Uso: } 3 \text { de } 5\end{array}$ \\
\hline $\mathrm{NIOSH}$ & $\begin{array}{l}\text { Este método foi descrito com as seguintes vantagens: fácil de usar } \\
\text { (opinião de 3/5), permite uma visão geral a respeito do índice de } \\
\text { levantamento de carga, ferramenta muito útil para avaliação da } \\
\text { carga (peso) a que um trabalhador está sujeito durante suas } \\
\text { atividades laborais (considerando o tipo de pega, distâncias } \\
\text { horizontais, verticais, etc), e tem comprovação científica. As } \\
\text { desvantagens estão em não poder utilizar o método se houver } \\
\text { variação de altura, ou distância percorrida com a carga superior a } \\
\text { dois passos; também é considerado muito simples por atender } \\
\text { apenas a situação imediata do posto, sendo superada pela } \\
\text { ferramenta NIOSH by OCRA. }\end{array}$ & $\begin{array}{l}\text { Média: } 4,2 \text { de } 5 \\
\text { Uso } 5 \text { de } 5\end{array}$ \\
\hline OCRA & $\begin{array}{l}\text { O método OCRA foi bem avaliado por ser um método completo, } \\
\text { indicado como uma das melhores ferramentas para indicar a } \\
\text { quantidade de pausas para a atividade. Porém, foi considerado } \\
\text { muito trabalhoso. }\end{array}$ & $\begin{array}{l}\text { Média: } 5 \text { de } 5 \\
\text { Uso: } 2 \text { de } 5\end{array}$ \\
\hline
\end{tabular}


Quadro 6 - Análise crítica dos métodos de avaliação ergonômica: vantagens e desvantagens práticas.

\begin{tabular}{|c|c|c|}
\hline Método & Análise crítica, vantagens e desvantagens & $\begin{array}{l}\text { 1- Insatisfeito a } \\
\text { 5- Muito Satisfeito }\end{array}$ \\
\hline OWAS & $\begin{array}{l}\text { Considerado de fácil utilização (3/5) e interpretação, recebeu as } \\
\text { seguintes vantagens: possibilita visão geral do quadro postural, } \\
\text { considerando a carga, a posição dos membros superiores e } \\
\text { inferiores, costas, regãa cervical, punhos, quadril, etc. São } \\
\text { desvantagens: dificuldade de aplicação em diversos casos, nível de } \\
\text { detalhamento reduzido em posturas específicas (determinados } \\
\text { segmentos corporais), demanda bastante tempo na análise, muito } \\
\text { simples e com déficit de informações; dependendo do foco, precisa } \\
\text { ser utilizado em associação a outro método (ex. REBA, RULA). }\end{array}$ & $\begin{array}{l}\text { Média: } 4 \text { de } 5 \\
\text { Uso: } 5 \text { de } 5\end{array}$ \\
\hline $\begin{array}{l}\text { Quest. } \\
\text { Bipolar }\end{array}$ & $\begin{array}{l}\text { Ferramenta de fácil aplicação para avaliar a fadiga. Porém, por ser } \\
\text { muito subjetivo, dependendo da resposta do colaborador, pode não } \\
\text { ser totalmente fidedigno (como muitos outros questionários). }\end{array}$ & $\begin{array}{l}\text { Média: } 3 \text { de } 5 \\
\text { Uso: } 2 \text { de } 5\end{array}$ \\
\hline REBA & $\begin{array}{l}\text { Ganhou pontos por oferecer uma visão detalhada, a nível de diagnose, } \\
\text { do quadro postural, com análise detalhada dos membros inferiores. } \\
\text { Segundo observações, é feito para uso em serviços médicos, o que } \\
\text { seria uma restrição. A única desvantagem relatada é não ser adequado } \\
\text { a todos os casos. }\end{array}$ & $\begin{array}{l}\text { Média: } 3,75 \text { de } 5 \\
\text { Uso: } 4 \text { de } 5\end{array}$ \\
\hline RULA & $\begin{array}{l}\text { É fácil de usar, avalia vários segmentos e tem um resultado bem } \\
\text { preciso, fazendo uma análise detalhada dos membros superiores (a } \\
\text { nível de diagnose). Entretanto, não é validado e, segundo a opinião dos } \\
\text { especialistas, apresenta erros, como por exemplo a rotação de punho, } \\
\text { que na verdade é rotação de cotovelo (pronação e supinação). } \\
\text { Também não se aplica a todos os casos. }\end{array}$ & $\begin{array}{l}\text { Média: } 3,8 \text { de } 5 \\
\text { Uso: } 5 \text { de } 5\end{array}$ \\
\hline $\begin{array}{l}\text { Suzane } \\
\text { Rodgers }\end{array}$ & $\begin{array}{l}\text { Segundo opiniões dos especialistas consultados, este método avalia } \\
\text { todos os segmentos do corpo em módulos separados, e também } \\
\text { oferece uma visão geral a respeito do quadro postural, sendo de fácil } \\
\text { aplicação. Citou-se a dificuldade de aplicação em uma variedade de } \\
\text { casos, o nível de detalhamento reduzido de posturas específicas } \\
\text { (determinados segmentos corporais), além de ser subjetivo, podendo } \\
\text { não ser totalmente fidedigno. }\end{array}$ & $\begin{array}{l}\text { Média: } 4,25 \text { de } 5 \\
\text { Uso: } 4 \text { de } 5\end{array}$ \\
\hline
\end{tabular}

Fonte: Elaborado pelo autor

Durante a pesquisa, questionou-se aos especialistas a indicação de outros métodos ergonômicos por eles utilizados que não constam no questionário. São eles: Diagrama de Corlett, Manenica, Plibel (checklist), TLV-NIOSH, Liberty Mutual, NIOSH by OCRA e SWAT. O método SWAT não foi incluído no questionário, e, portanto, não há revisão crítica por parte dos especialistas. Quando perguntados sobre qual método considerou-se mais adequado para determinada avaliação, obteve-se as indicações dos especialistas contidas no Quadro 7. 
Quadro 7 - Métodos recomendados pelos especialistas de acordo com o objetivo de avaliação

\begin{tabular}{|l|l|}
\hline Objetivo da avaliação & Método recomendado pelos especialistas \\
\hline Avaliação de risco & OCRA, Checklist de Couto, RULA, NIOSH by OCRA, AET e OWAS \\
\hline Carga física & NIOSH, Liberty Mutual e Suzane Rodgers \\
\hline Carga mental & NASA-TLX, Questionário Bipolar e SWAT \\
\hline Carga temporal & NASA-TLX e Suzane Rodgers \\
\hline Avaliação da dor & Diagrama de Corlett, manenica, e métodos combinados \\
\hline Condições ambientais & AET e OWAS \\
\hline Postos de trabalho & $\begin{array}{l}\text { Checklist de Couto combinado a outros métodos, AET, OWAS, NIOSH, } \\
\text { RULA, REBA, Diagrama de Corlett, manenica e JSI (Moore and Garg) }\end{array}$ \\
\hline Avaliação postural & RULA, REBA, OWAS, Suzanne Rodgers e Checklist de Couto \\
\hline Repetitividade & OCRA, REBA e RULA \\
\hline Fonte: Elaborado pelo autor
\end{tabular}

É relevante citar que um dos especialistas, ao ser questionado sobre a adequação dos métodos, repetiu a mesma resposta para quase todas as questões (exceto para risco): "O adequado é a integração de abordagens de técnicas (qualitativas, a nível subjetivo, de percepção dos pesquisados; semi-quantitativa, pela visão do pesquisador, ainda que subjetivo, há referência para a análise, como uma fórmula ou parâmetros biomecânicos e; quantitativos, com abordagem quantitativa, objetiva, sem a interferência de subjetividade)".

\subsection{Análise crítica dos métodos e perspectivas para novas abordagens}

A consulta à base de dados permitiu ranquear os métodos com maior número de publicações associadas, em busca de identificar os métodos mais comumente usados na pesquisa científica. Já a etapa de consulta a especialistas trouxe os métodos mais usados e aceitos pelos profissionais respondentes. Ao comparar ambas as etapas, constatou-se que os métodos mais incidentes em publicação também são os mais utilizados e bem aceitos pelos ergonomistas. Embora a consulta aos especialistas gere resultados semelhantes à pesquisa quantitativa, sua maior contribuição é de caráter qualitativo, cujas percepções fundamentam a análise crítica dos métodos de avaliação ergonômica sob a luz da literatura.

Os métodos que apresentaram frequência relativa (maior número de publicações associadas) superior a $2 \%$ foram seis: NIOSH, fanger, NASA-TLX, OWAS, REBA e RULA. O método NIOSH foi utilizado por todos os profissionais pesquisados, recebendo uma nota média de 4,2 pontos, o que indica ser um método 
amplamente utilizado, validado cientificamente e consagrado pelos profissionais diversos da ergonomia.

O método Fanger, que obteve o segundo maior número de publicações relacionado, é utilizado para avaliar o conforto térmico. Entretanto, na pesquisa com os especialistas, nenhum dos profissionais de ergonomia o havia utilizado. A publicação de legislação e normas relacionadas ao ambiente térmico, pela ISO (International Organization for Standartization) e pela ASHRAE (Amercian Society for Heating, Refrigeration and Air-Conditioning Engineers), através, por exemplo, da ISO 7730, NBR 16401 e NR17, consolida a importância do conforto térmico em ambientes de trabalho para garantir a saúde do trabalhador (TALAIA, 2013). Porém, a não aplicação deste método dentre os profissionais pesquisados ocorre devido à sua utilização comum na concepção dos produtos e processos. Ou seja, ele está presente na construção civil, na fabricação de aparelhos de climatização, roupas, automóveis, aviões, entre outros, atuando de forma a construir ambientes adequados ao homem antes mesmo do trabalho, ou seja, adequando os ambientes/produto ao homem. Todavia, também pode ser utilizado para avaliar a sensação de conforto térmico em ambientes já construídos, a fim de proporcionar um posto de trabalho termicamente adequado ao trabalhador.

O método NASA-TLX ficou em terceiro na tabela de frequências, e obteve nota média de 4,3 pontos, tendo sido utilizado por 3 dos cinco profissionais pesquisados. É um método utilizado para avaliação de carga mental, e conforme apontamentos da revisão bibliográfica e opinião dos especialistas, é eficiente e traz resultados bem aprofundados. Apesar de ter sido considerado como de difícil interpretação pelos profissionais, em estudo comparativo entre os métodos NASATLX e SWAT, Cardoso (2012) relatou ser o NASA-TLX mais simples que seu semelhante (ambos avaliam carga mental).

O quarto método mais frequente na literatura (nesta amostra) foi o OWAS, que realiza avaliação postural do trabalhador. Este método foi utilizado por todos os profissionais, e recebeu nota média de 4 pontos. Segundo os especialistas, possui diversas vantagens, entretanto não cobre todas as situações posturais e às vezes requer ser utilizado em associação a outro método de avaliação postural. De acordo com a revisão de literatura, é validado cientificamente, é fácil de usar pois realiza 
uma análise de imagem em campo ou por vídeo e está presente em diversos softwares de avaliação ergonômica.

O método REBA ficou em quinto lugar nas publicações, tendo recebido nota média de 3,75 pontos, sendo utilizado por 4 dos 5 profissionais. Oferece uma avaliação detalhada do quadro postural do trabalhador, entretanto, não se aplica a todos os casos. Foi desenvolvido a partir dos métodos RULA e OWAS, e oferece 5 níveis de ação (1 a mais que o método RULA).

Por fim, em sexto lugar, o último método com frequência relativa superior a 2\%, está o método RULA. Pertencente ao grupo dos métodos de avaliação postural, obteve nota média de 3,8 pontos, e foi utilizado por todos os especialistas consultados. Enquanto oferece precisão e detalhamento, não é validado e possui alguns erros de especificação. Na revisão de literatura, recomenda-se o seu uso para avaliar repetitividade. Foi projetado a partir do método OWAS (4 ${ }^{\circ}$ em frequência), e tem por base a análise de imagens.

\section{CONCLUSÕES}

São muitas as ferramentas, métodos e normas de ergonomia disponíveis a fim de auxiliar no processo de avaliação ergonômica do trabalho, sendo complexo definir as mais adequadas, afirmação esta reforçada por lida (2005). Atributos tais como validade científica, facilidade de aplicação, recomendação profissional e popularidade, combinadas às experiências, perfil (habilidades) e expectativas do ergonomista, interferem na escolha do método a ser aplicado. Ainda, essa diversidade de métodos, de múltiplas finalidades, dificulta o processo de escolha da ferramenta pelo profissional a fim de definir as que melhor se aplicam. Portanto, entende-se que o levantamento e a classificação das ferramentas fornecem opções ou reforçam os atuais critérios de escolha dos métodos pelos especialistas.

Este estudo indica uma necessária reorganização dos métodos existentes, buscando concentrar, de forma clara e acessível, as ferramentas semelhantes, de modo a dar suporte ao profissional, na escolha dos métodos. Ao organizar esses instrumentos, é possível potencializar as escolhas do especialista, gerando avaliações mais completas (combinação de métodos), podendo aumentar a 
fidelidade dos resultados e, consequentemente, gerar adequações mais eficientes, resultando em saúde e produtividade.

Sugere-se, em estudos futuros, realizar investigação mais profunda dos métodos, realizando-a em etapas que representem grupos de atuação, como por exemplo, os métodos de avaliação postural, de carga mental, de posto de trabalho, entre outros, observando e mapeando suas semelhanças e diferenças. Por fim, foram identificados muitos métodos semelhantes, derivados ou associados entre si para a realização de um diagnóstico específico, sendo necessário compreender como o processo de avaliação ergonômica acontece, a fim de propor melhorias ao processo, buscando compreender as possibilidades de uma nova abordagem de interface entre especialista e ferramenta (estudos futuros). Sugere-se ainda que outros estudos contemplem um número mais expressivo de respondentes, aumentando a confiabilidade dos resultados encontrados.

Destaca-se ainda, nesta última seção, que durante a etapa de resultados, houve uma consulta intermitente à literatura, onde outros métodos de avaliação ergonômica foram identificados, sendo aqui listados e sugerida a sua investigação futura, junto àqueles apontados pelos especialistas na seção 3.1. São eles: diagrama de ARMSTRONG (1982, análise de tarefas com membros superiores), checklist de Michigan (1986, fatores de risco), checklist de Keyserling (1993, riscos associados aos membros superiores), HAMA (1994, custo postural das mãos e braços), ARBAN (1982, análise ergonômica do trabalho), Malchaire (1998, riscos musculoesqueléticos) e IEA (1999, movimentos permitidos por minuto).

\section{REFERÊNCIAS}

AKAIKE, $\mathrm{H}$. 'A new look at the statistical model identification'. IEEE Transactions on Automatic Control v. 19, p. 716-723, 1974. DOI: https://doi.org/10.1109/TAC.1974.1100705

ALAHMAER, Ali. et al. Analysis of vehicular cabins' thermal sensation and comfort state, under relative humidity and temperature control, using Berkeley and Fanger models.

Building and Environment. United States, 2012.

APTEL, Michel et al. Proposal of parameters to implement a workstation rotation system to protect against MSDs. International Journal of Industrial Ergonomics, v.38, p.900-909. Dezembro de 2008.

BARROS, Ruberth A. A. Sistema para análise ergonômica do trabalho com uso de câmeras de profundidade. JORNADA DE INFORMÁTICA DO MARANHÃO, Anais... 2014. 
CABEÇAS, José Miquel. The risk of distal upper limb disorder in cleaners: A modified application of the Strain Index Method. International Journal of Industrial Ergonomics, v.37, p. 563-571, jun. 2007.

CALLEJÓN-FERRE, A. J. et al. Ergonomics and psycho-sociological quality indeces in greenhouses. Spanish Journal of Agricultural Research, Almería, Espanha 2009.

CARDOSO, Mariane de Souza. GONTIJO, Leila Amaral. Avaliação da carga mental de trabalho e do desempenho de medidas de mensuração: NASA TLX e SWAT. Revista Gestão \& Produção, v.19, n.4, p. 873-884. São Carlos, 2012.

CARDOSO JR, Moacyr Machado. Avaliação Ergonômica: Revisão dos métodos para avaliação postural. Revista Produção online v. 6, n. 3, dez. 2006.

CARVALHO, Alex Luis. MENEGON, Nilton Luiz. A pertinência dos documentos prescritos nas atividades dos profissionais de manutenção industrial: o caso de uma indústria automobilística. Revista Gestão \& Produção, v. 21, n. 1, p. 143-155. São Carlos, 2014.

CCOO - Comissió Obrera Nacional de Catalunya. Curso Básico de Salud Laboral. Disponível em: www.ccoo.cat/pdf documents/SL\%2022\%20Evaluaci\%C3\%B3n\%20de\%20Riesgos.pdf. Acesso em: 08 jan. 2015.

CHIASSON, Marie-Ève et al. Comparing the results of eight methods used to evaluate risk factors associated with musculoskeletal disorders. International Journal of Industrial Ergonomics, v.42, p. 478-488, Setembro de 2012.

COLOMBINI, Daniela. OCCHIPINTI, Enrico. Preventing upper limb work-related musculoskeletal disorders (UL-WMSDS): New approaches in job (re)design and current trends in standardization. Applied Ergonomics, v.37, jul. 2006.

COSTA, Christiane Kelen Lucena da. et al. Avaliação Ergonômica do trabalhador rural: enfoque nos riscos laborais associados à carga física. Revista GEPROS - Gestão da Produção, Operações e Sistemas, Ano 6, n. 2, 2011.

COSTA, Josiane Ferreira. SOUZA, Sueli Tavares de Melo. Projeto ergonômico das condições de segurança e saúde no trabalho em uma empresa de montagem de chicotes elétricos. Projética, v.5, n.2. Londrina - Paraná, dezembro de 2014.

DEFANI, Junior Clacindo. Avaliação do perfil antropométrico e análise dinamométrica dos trabalhadores da agroindústria do setor de frigoríficos do setor de frigoríficos e abatedouros: o caso da Perdigão - Carambeí. Dissertação (Mestrado) - Programa de pósgraduação em engenharia de produção - UTFPR, Ponta Grossa, 2007.

DIEGO-MÁS, José Antonio. CUESTA, Sabina Asensio. LEST (Laboratorio de Economia y Sociologia del Trabajo). Universidad Politecnica de Valencia. Disponível em: http://www.ergonautas.upv.es/metodos/LEST/LEST-ayuda.php Acessado em janeiro de 2015.

DOCKRELL, Sara et al. An investigation of the reliability of Rapid Upper Limb Assessment (RULA) as method of assessment of children's computing posture. Applied Ergonomics, $n$. 43, 2012. 
DOUWES, M., KRAKER, H. de. Development of a non-expert risk assessment method for hand-arm related tasks (HARM). International Journal of Industrial Ergonomics, v.44, p.316-327. Março de 2014.

DUL, Jan. WEERDMEESTER, B. A. Ergonomia prática. 2.ed. ver. e ampl. São Paulo: Editora Blücher, 2004.

ERGO, Cadernos. Gestão da Qualidade no PCMSO. Equação do NIOSH para Levantamento Manual de Cargas. Ergo Editora Ltda. Ergonomia, Saúde e Segurança n.1, out./dez. 2006.

ETUI - Instituto Sindical Europeu. Guia: classificação dos métodos de avaliação e/ou prevenção dos riscos de Distúrbios Osteomusculares Relacionados ao Trabalho (DORT).

FALCÃO, Franciane da Silva. Métodos de avaliação biomecânica aplicados a postos de trabalho no pólo industrial de Manaus (AM): uma contribuição para o design ergonômico. Universidade Estadual Paulista Júlio de Mesquita Filho. Bauru, SP, 2007.

GUÉRIN, F. et. al. Compreender o trabalho para transformá-lo: a prática da ergonomia. São Paulo: Editora Edgard Blucher Ltda, 2006.

GUIMARÃES, Lia Buarque de Macedo. Ergonomia de produto: antropometria, fisiologia e biomecânica. Porto Alegre, RS, 2004.

IIDA, Itiro. Ergonomia: projeto e produção. 2. ed. São Paulo: Editora Blucher, 2005.

INSHT, Instituto Nacional de Seguridad e Higiene en el trabajo. Tarefas repetitivas: método Ergo/IBV de evaluación de riesgos ergonómicos. Notas Técnicas de Prevención nº 844. Ano de publicação: 2009.

KEE, Dohyung. KARWOWSKI, Waldemar. LUBA: an assessment technique for postural loading on the upper body based on joint motion discomfort and maximum holding time. Applied Ergonomics, v.32 p. 357-366, ago. 2001.

LAVILLE, Antoine. Ergonomia. São Paulo: Editora Pedagógica e Universitária Ltda, 1977.

LIMA, João Ademar de Andrade. Metodologia de análise ergonômica. Monografia (Especialização) - UFPB, João Pessoa, 2003.

LIMA, João Ademar de Andrade. Bases teóricas para uma metodologia de análise ergonômica. PUC-RJ. ERGODESIGN - CONGRESSO INTERNACIONAL DE ERGONOMIA E USABILIDADE DE INTERFACES HUMANO-TECNOLOGIA: PRODUTOS, PROGRAMAS, INFORMAÇÃO, AMBIENTE CONSTRUÍDO, 4., 2004. Anais... Rio de Janeiro - RJ, maio de 2004.

MACÊDO, Cristianne Silva et al. Avaliação do índice TOR-TOM no processo de soldagem em indústria automotiva de duas rodas do Pólo Industrial de Manaus. INGEPRO - Inovação, Gestão e Produção, 2010.

MÁSCULO, Francisco Soares. VIDAL, Mario Cesar, (Orgs). Ergonomia: trabalho adequado e eficiente. Rio de Janeiro: Elsevier / ABEPRO 2011.

MICHAELIS. Dicionário de português online. Editora Melhoramentos, 2009. 
TEM. Ministério do Trabalho e Emprego. http://portal.mte.gov.br. Dezembro, 2014.

NAKANO, Davi. Metodologia de pesquisa em engenharia de produção e gestão de operações. 2. ed. Rio de Janeiro: Elsevier: ABEPRO, 2012.

OLIVEIRA, Graciela Santos J. F. et al. Conforto térmico no ambiente de trabalho: avaliação das variáveis subjetivas da percepção do calor. SEGET - SIMPÓSIO DE EXCELÊNCIA EM GESTÃO E TECNOLOGIA, 7, 2010. Anais...

OSHA. Agência europeia para a segurança e saúde no trabalho: a ferramenta KIM: método Indicador chave. Acessado em: 09 de janeiro de 2015. Disponível em: https://osha.europa.eu/pt/topics/msds/slic/handlingloads/19.htm

PACOLLA, Sileide A. de Oliveira. SILVA, José Carlos Plácido. Revisão de Metodologias de Avaliação Ergonômica Aplicadas à Carteira Escolar: uma abordagem analítica e comparativa. Revista Design e Ergonomia: aspectos tecnológicos (online). São Paulo, 2009.

PESSA, Sergio L. R. Análise do trabalho nos três turnos do setor de corte e solda e impressão de uma indústria de embalagens plásticas flexíveis de alimentos, considerando o cronotipo do trabalhador. 2010. Tese (Doutorado) - Programa de Pós Graduação em Engenharia de Produção, UFRGS, 2010.

REID, G. B., EGGEMEIER, F.T. e SHINGLEDECKER, C. A. Frazier and R.B. Crombie (Eds). Proceeding of the workshop on flight testing to identify pilot workload and pilot dynamics. AFFTC-TR-82-5, 1982. Acesso em: http://www.dtic.mil/dtic/tr/fulltext/u2/a129333.pdf

ROMAN-LIU, Danuta. Comparison of concepts in easy-to-use methods for MSD risk assessment. Applied Ergonomics, v. 45, p. 420-427. Maio de 2014.

SNYDER, Ralph D. ORD, Keith. Exponential smoothing and the akaike information criterion. Department of Econometrics and Business Statistics. Junho de 2009.

SOARES, Elaine Victor Gonçalves. SILVA, Liane Marcia Freitas e. Estudo ergonômico e propostas de melhorias em postos de trabalho de uma empresa de mineração. VII SEPRONe - SIMPÓSIO DE ENGENHARIA DE PRODUÇÃO DA REGIÃO NORDESTE. Mossoró-RN, 7., 2012. Anais....

SONNE, Michael et al. Development and evaluation of an office ergonomic risk checklist: ROSA - Rapid office strain assessment. Applied Ergonomics, v.43, p. 98-108, jan. 2012.

TALAIA, Mário et al. Riscos naturais antrópicos e mistos. UC - Universidade de Coimbra. Livro-homenagem ao professor doutor Fernando Rebelo. Coimbra, 2013. Disponível em: http://www.uc.pt/fluc/depgeo/Publicacoes/livro_homenagem_FRebelo/. Acesso em: janeiro de 2015.

WISNER, A. Por dentro do trabalho. São Paulo: FTD/Oboré, 1987.

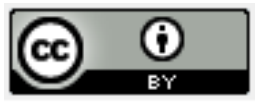

Artigo recebido em 19/06/2017 e aceito para publicação em 01/12/2017 DOI: http://dx.doi.org/10.14488/1676-1901.v18i2.2925 